\title{
Review: exercise training delays death and hospital admission in chronic heart failure
}

Piepoli MF, Davos C, Francis DP, et al. Exercise training meta-analysis of trials in patients with chronic heart failure (ExTraMATCH). BMJ 2004;328:189-92.

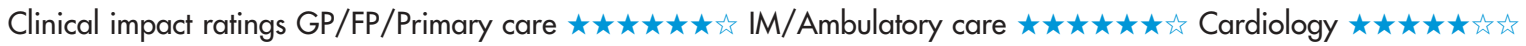

In patients with chronic heart failure (CHF) resulting from left ventricular systolic dysfunction, does exercise training reduce death or admission to hospital?

\section{METHODS}

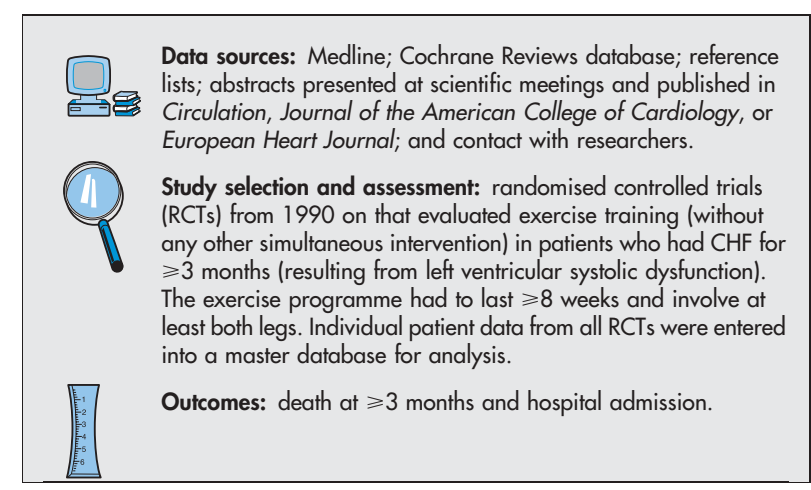

\section{MAIN RESULTS}

9 RCTs ( 8 from Europe) met the selection criteria. Sample size ranged from 27-181 patients, and the training programme lasted from 8 weeks to $\geqslant 1$ year (mean follow up 159-2284 d). Time to death (median $618 v 421 \mathrm{~d}$ ) and hospital admission (median $426 v 37 \mathrm{ld}$ ) were longer in the exercise group than in the usual care group (table).

\section{CONCLUSION}

In patients with chronic heart failure resulting from left ventricular systolic dysfunction, exercise training delayed death and hospital admission.

\begin{tabular}{lllll} 
Exercise training $v$ usual care for chronic heart failure* \\
\hline $\begin{array}{l}\text { Outcomes at } \\
\text { mean 159-2284 } \\
\text { days }\end{array}$ & $\begin{array}{l}\text { Exercise } \\
\text { training }\end{array}$ & $\begin{array}{l}\text { Usual } \\
\text { care }\end{array}$ & RRR (95\% CI) & NNT (CI) \\
\hline Death & $22 \%$ & $26 \%$ & $\begin{array}{l}32 \% \\
(6.9\end{array}$ to 50) & 13 (8 to 56) \\
$\begin{array}{l}\text { Death or hospital } \\
\text { admission }\end{array}$ & $32 \%$ & $43 \%$ & $\begin{array}{l}23 \% \\
(5.3 \text { to } 37)\end{array}$ & 11 (7 to 44) \\
\hline
\end{tabular}

*Abbreviations defined in glossary; RRR, NNT, and Cl calculated from hazards ratio in article.

For correspondence: $\mathrm{Dr} M$ F Piepoli, Royal Brompton Hospital, London, UK m.piepoli@imperial.ac.uk

Source of funding: Royal Brompton and Harefield NHS Trust Clinical Research Committee.
Commentory

A ctivity intolerance is a hallmark of CHF. Until relatively recently, CHF patients were advised to limit their activity to protect the damaged heart. We have since learned that in selected patients exercise training programmes are not only safe but also can reverse many of the peripheral abnormalities thought to play a role in exercise intolerance and improve exercise capacity. However, these studies have generally been small and of short duration and have used physiological endpoints. The question of whether exercise training reduces mortality and morbidity in CHF patients remains unresolved. The ExTraMATCH Collaborative addressed this question using individual patient data from 9 relatively small studies published since 1990 and involving 801 patients. As anyone who has attempted this type of analysis well recognises, this can be a difficult and arduous task for both the organisers and the investigators, especially since the endpoints of death and hospital admission for CHF were not primary or even, in most cases, secondary endpoints in these studies. The authors are certainly to be congratulated for this effort. Their analyses show relative risk reductions of $32 \%$ for death and $23 \%$ for death or CHF hospital admission, respectively, with exercise training compared with usual care (hazard ratios of 0.65 and 0.72 , with $95 \%$ confidence intervals that do not cross unity). Effect sizes such as these compare favourably with the best pharmacological treatments for CHF.

There are, however, important limitations to the individual studies themselves and to the presentation of the information in this review. Firstly, these studies are necessarily unblinded. Secondly, they were, with 1 apparent exception, single centre studies with substantial emotional and intellectual investment by the investigators. Combining such studies does not eliminate the potential for bias in this setting. Thirdly, endpoint data are not available to readers for 5 of the 9 RCTs. Without the individual study data, it is difficult to assess the robustness of the results. Of the 2 largest studies with endpoint data, one (McKelvie) found no difference in mortality and the other (Belardinelli) reported a very large difference favouring training ( $9 \vee 20$ deaths). With 88 deaths in the exercise arm and 105 in the control arm in total, this latter study accounted for most of the overall treatment difference. And lastly, centres differed substantially in the nature, intensity, duration, and supervision of the exercise intervention, making it impossible to assess whether the apparent beneficial effects of exercise were linked to the intervention.

Because of these limitations, this review does not provide convincing evidence for a beneficial effect of exercise training on mortality and morbidity, although, as the authors note, it further supports its safety. None the less, these results generate additional enthusiasm for research into how training may affect outcomes and for conducting a definitive outcome trial. Fortunately, a 3000 patient multicentre trial, Heart Failure and A Controlled Trial Investigating Outcomes of Exercise TraiNing (HFACTION), sponsored by the National Heart, Lung, and Blood Institute, is now ongoing in North America and Europe.

Barry Massie, MD University of California San Francisco, California, USA 